\title{
Treatment of resistant epilepsy
}

\author{
Authors: William Owen Pickrell ${ }^{A}$ and Phil EM Smith ${ }^{B}$
}

\section{Treatment resistance affects around $20 \%$ of people with epilepsy and carries a significant comorbidity. It is important to ensure that the diagnosis of epilepsy is secure and the underlying cause of the epilepsy is investigated thoroughly. Management involves early referral for epilepsy surgery when suitable, optimisation of pharmacological treatment, and consideration of comorbidities such as depression.}

KEYWORDS: Epilepsy, treatment resistance, management

\section{Introduction}

Epilepsy is defined as an ongoing tendency to experience unprovoked epileptic seizures, with a prevalence in developed countries of around $1 \%$. Although most people's epilepsy can be controlled successfully with one or two anti-epileptic drugs (AEDs), around $20 \%$ of people with epilepsy will have treatment-resistant or drug-resistant epilepsy. ${ }^{1}$ Drug resistance can be defined as 'failure of adequate trials of two tolerated, appropriately chosen and used anti-epileptic drug schedules - whether as monotherapy or in combination - to achieve sustained seizure freedom'.2

Risk factors for developing drug-resistant epilepsy include a higher number of seizures at the time of diagnosis and symptomatic epilepsy (epilepsy with a known, often structural, cause). ${ }^{3,4}$ It is still not clear why a significant minority of people with epilepsy develop drug-resistant epilepsy, although this probably relates to the heterogeneity of epilepsy and its underlying complex genetic aetiology. Plausible explanations include a genetic predisposition for reduced uptake of AEDs, reduced expression of AED targets, or differing mechanisms for epileptogenesis in people with drug-resistant epilepsy. ${ }^{5}$

Uncontrolled seizures are associated with significant comorbidity, including reduced quality of life, increased risk of anxiety and mood disorders, ${ }^{6}$ impaired cognitive function, ${ }^{7}$ and increased risk of premature death. ${ }^{8}$ The prognosis for people with drug-resistant epilepsy has historically been poor: in a 40-year prospective study of 102 children with resistant epilepsy,

Authors: ${ }^{A}$ Welsh clinical academic trainee, Neurology and Molecular Neuroscience Research Group, College of Medicine, Swansea University, Swansea, UK, and Welsh Epilepsy Centre, University Hospital of Wales, Cardiff, UK; B Consultant neurologist, Wales Epilepsy Centre, University Hospital of Wales, Cardiff, UK
$82 \%$ had 1 year of seizure freedom although only $51 \%$ had continuing seizure freedom. ${ }^{9}$

The clinician must consider many things when managing a patient with possible drug-resistant epilepsy, including alternative diagnoses, early referral for potentially curative surgical treatment and selection of the appropriate pharmacological management. This article outlines a pragmatic clinical approach to managing resistant epilepsy in adults, as outlined in Fig 1.

\section{Is the diagnosis correct?}

There is no single 'test' for epilepsy and its diagnosis can sometimes be difficult, even in experienced hands. The misdiagnosis rate in people referred to specialist centres with a diagnosis of drug-resistant epilepsy may approach $30 \% .^{10,11}$ The most common epilepsy 'mimics' are syncope (reflex and cardiogenic), and non-epileptic or dissociative seizures (previously called pseudo- or psychogenic seizures). Rarer epilepsy mimics include paroxysmal movement disorders, sleep disorders and metabolic disorders. ${ }^{12}$

Non-epileptic seizures are typically caused by a psychogenic dissociative process, rather than by the abnormal electrical activity of epileptic seizures. Non-epileptic seizures may account for up to $25 \%$ of cases of drug-resistant epilepsy ${ }^{10}$ and perhaps pose the greatest diagnostic dilemma, even to specialist epileptologists. The diagnosis is often even harder in the $10 \%$ of those with non-epileptic seizures who also have epileptic seizures. ${ }^{13}$ Table 1 summarises some key clinical features that can help to differentiate epileptic from non-epileptic seizures..$^{13}$ Paying particular attention to the consultation conversation may also help. For example, people with epileptic seizures tend to volunteer information about their seizures and make attempts to describe them in as much detail as possible. People with non-epileptic seizures find it harder to describe details involving the seizures, tending instead to focus on the circumstances surrounding the seizure, rather than the seizure itself. ${ }^{14}$

\section{Investigating the cause of the epilepsy}

Epilepsy is not a single disease but may be caused by a variety of underlying brain disorders or injuries, each increasing the tendency to experience epileptic seizures. The clinician must make every effort to uncover the underlying cause of the epilepsy to guide treatment strategies and to inform prognosis.

When managing drug-resistant epilepsy, it is worth taking or retaking a detailed 'epilepsy history', looking for clues to the cause of the epilepsy (Table 2 highlights some of these). All patients with resistant epilepsy should have had 


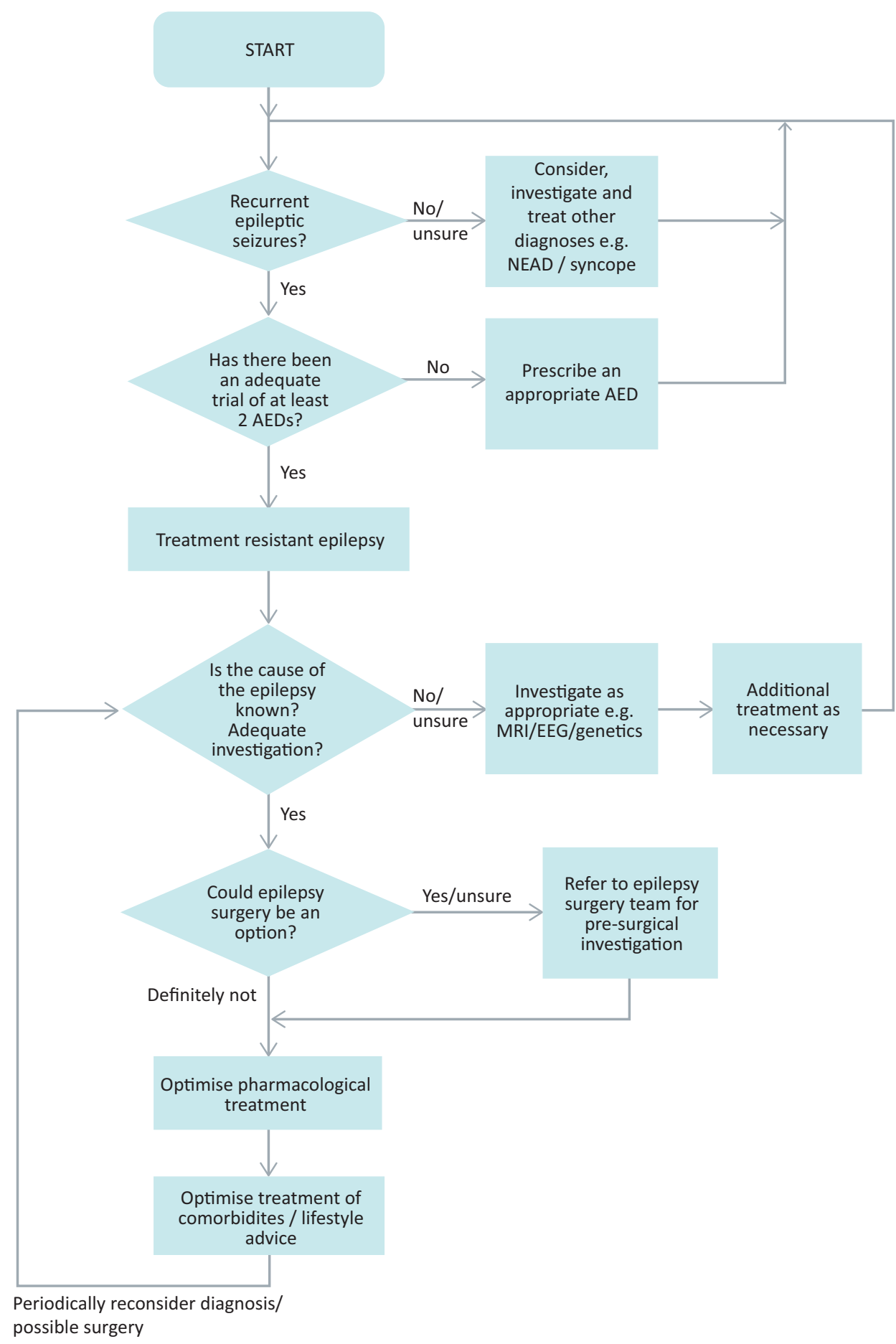

Fig 1. Suggested algorithm for managing drug-resistant epilepsy. $\mathrm{AED}=$ antiepileptic drug; NEAD = non-epileptic attack disorder; $M R I=$ magnetic resonance imaging; $\mathrm{EEG}=$ electroencephalogram.

a magnetic resonance imaging (MRI) scan of their brain to look for potential structural causes of the epilepsy, unless the diagnosis of genetic generalised epilepsy is certain. ${ }^{15}$ If possible, a neuroradiologist should report the scan to maximise the chances of identifying a subtle epileptogenic lesion.

An electroencephalogram (EEG) is generally not as useful as brain imaging, but can still provide useful information. EEGs can support the diagnosis of a generalised epilepsy or photosensitivity, help to localise focal epilepsies and occasionally may help confirm the diagnosis of non-epileptic seizures if a typical seizure is captured without corresponding epileptiform changes. Repeat EEGs or sleep-deprived EEGs can sometimes yield useful diagnostic information. ${ }^{15}$ Video recordings taken by patients' family members or carers can sometimes help. Video telemetry EEG monitoring is perhaps the gold standard investigation and, if available, is worth requesting in difficult cases. 
Table 1. Some key clinical features that may help to differentiate epileptic seizures from non-epileptic seizures. ${ }^{13}$

$\begin{array}{lll}\text { Feature } & \text { Epileptic seizures } & \text { Non-epileptic/dissociative seizures } \\ \text { Nature } & \text { Predominately stereotypical } & \text { Typically lack consistency } \\ \text { Occurrence during sleep } & \text { Can occur from sleep } & \text { Rarely occur from sleep } \\ \text { Eyes } & \text { Rarely closed } & \text { Can be closed } \\ \text { Duration } & \text { Rarely longer than seconds to minutes } & \text { Can be several to tens of minutes in duration } \\ \text { Breathing } & \text { Typically apnoeic in expiration } & \text { May have rapid breathing or breath hold in inspiration } \\ \text { Colour } & \text { May be cyanosed, pale or flushed } & \text { Rarely cyanosed } \\ \text { Amplitude of movements } & \text { Tend to reach maximum then decrease } & \text { Can 'wax and wane' } \\ \text { Seizure frequency } & \text { Typically unpredictable and can 'cluster' } & \text { Frequency can be regular } \\ \text { Injuries } & \text { Can sustain injuries and lateral tongue bites during seizures } & \text { Rarely sustain injuries or lateral tongue bites }\end{array}$

Table 3 gives examples of rare conditions requiring more specialist investigations, for example genetic tests. Although rare, these diagnoses are worth considering as sometimes there are condition-specific treatment options available.

\section{Surgical treatment}

Clinicians should consider surgery as soon as possible for patients with drug-resistant focal epilepsy, as earlier surgery can improve outcomes. ${ }^{16}$ The chance of obtaining seizure freedom with surgery is significantly higher than with medical therapy. In one long-term study of 615 patients undergoing epilepsy surgery, $50 \%$ remained seizure free after 10 years. ${ }^{17}$

Traditionally, curative epilepsy surgery has been considered the most suitable option for a patient with drug-resistant epilepsy who has a definitive epileptogenic lesion on an MRI scan, most commonly hippocampal sclerosis or mesial temporal sclerosis (Fig 2). Although there needs to be conclusive evidence of a resectable epileptogenic zone before proceeding to surgery, advances in imaging technology and the development of techniques such as intracranial EEG monitoring mean that surgery is possible for some patients with focal epilepsy and a normal MRI scan. A recent retrospective study found that $28 \%$ of patients referred with drug-resistant MR scan-negative extratemporal lobe epilepsy underwent surgery: $33 \%$ were seizure free and $75 \%$ had a worthwhile seizure improvement a mean of 9 years after surgery. ${ }^{18}$

Vagus nerve stimulators are surgically implanted batterypowered devices that repeatedly stimulate the vagus nerve. The devices are similar in size to cardiac pacemakers and are implanted in the upper chest with connecting wires attached to the left vagus nerve in the carotid sheath. Vagus nerve stimulation can be considered as an adjunctive therapy in patients with drug-resistant epilepsy with focal or generalised epilepsy who are not suitable for resective surgery. ${ }^{15}$ Around $50 \%$ of patients experience a reduction in seizure frequency

\section{Table 2. Important topics to cover when taking an 'epilepsy history'}

\begin{tabular}{|c|c|c|}
\hline Topic & Areas to cover & Relevance \\
\hline \multirow[t]{3}{*}{ Remote history } & $\begin{array}{l}\text { Birth history } \\
\text { Significant CNS infections } \\
\text { Significant head trauma }\end{array}$ & Potential causes of symptomatic structural epilepsy \\
\hline & Febrile seizures & Increased risk of adult epilepsy \\
\hline & & Genetic epilepsy with febrile seizures plus (GEFS+) \\
\hline \multirow[t]{2}{*}{ Seizure history } & $\begin{array}{l}\text { Age at onset of different seizure } \\
\text { types Frequency of seizure types } \\
\text { Description of typical seizures }\end{array}$ & $\begin{array}{l}\text { Identification of a defined epilepsy syndrome (eg juvenile } \\
\text { myoclonic epilepsy) } \\
\text { Classification of seizure type (eg temporal lobe epilepsy) }\end{array}$ \\
\hline & Provoking/alleviating factors & Reflex epilepsies (eg photosensitive epilepsy) \\
\hline \multirow[t]{2}{*}{ Medical/drug history } & Comorbidities & Potential causes of symptomatic epilepsy (eg stroke) \\
\hline & Medication history & Some drugs can lower seizure threshold (eg tramadol) \\
\hline Family history & $\begin{array}{l}\text { Epilepsy } \\
\text { Other comorbidities } \\
\text { Sudden/unexplained deaths }\end{array}$ & $\begin{array}{l}\text { Familial epilepsy syndromes } \\
\text { Other genetic syndromes } \\
\text { Genetic cardiac conditions as epilepsy mimics }\end{array}$ \\
\hline Social history & $\begin{array}{l}\text { Concomitant alcohol/recreational drug use } \\
\text { Occupation/shift work }\end{array}$ & Potential seizure triggers \\
\hline
\end{tabular}




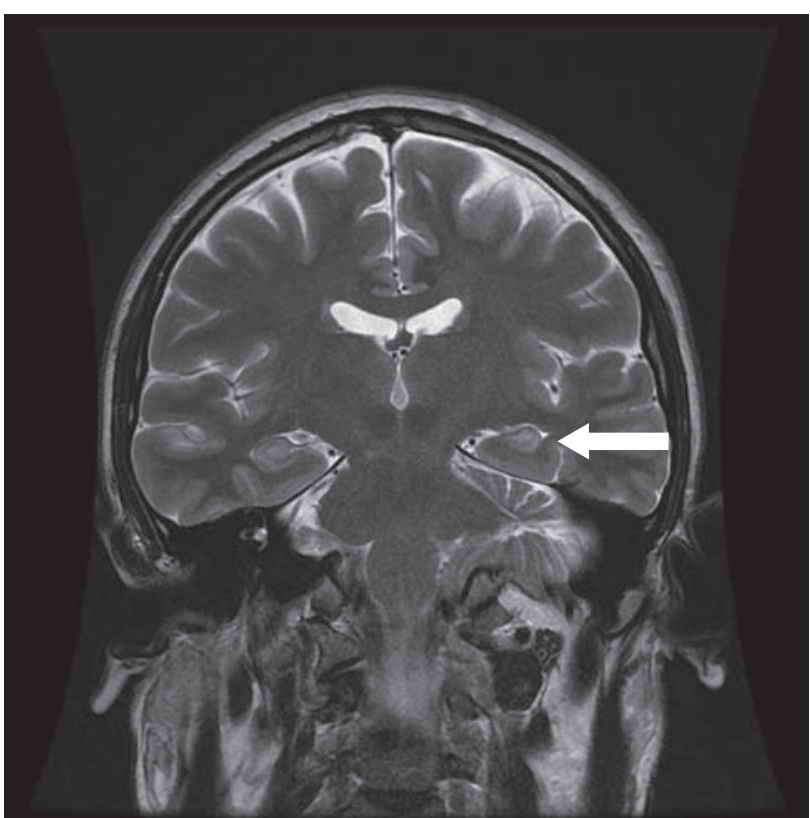

Fig 2. MRI scan of left hippocampal sclerosis (note the asymmetry in size when compared with the right [arrowed]). MRI = magnetic resonance imaging.

after vagus nerve stimulator insertion however, around 25\% have no change in seizures at all and complete seizure remission is rare $(<5 \%) .{ }^{19}$ It is also important to remember the potential side effects of vagus nerve stimulation, including voice change and cough; the finite battery life necessitating device change every 10 years or so; and the inability to have an MRI scan with a vagus nerve stimulator in situ - an important consideration if the option of surgery is to be reconsidered in future.

\section{Medical treatment}

Medical treatment is currently the mainstay for patients who are not suitable for surgery, have refused surgery, or have developed seizure recurrence following surgery. Patients with resistant epilepsy understandably often become wary of repeated medication changes if they have tried several in the past, only to accumulate new side effects with little change in seizure frequency or (more importantly) quality in life. There is, however, a small but significant chance of benefit when trying medication changes. Around 5\% of patients with drug-resistant epilepsy will become seizure free each year with medication changes (compared to $0.4 \%$ without)..$^{20}$ Among one group of patients with chronic epilepsy, $16 \%$ of drug introductions made by an experienced epileptologist resulted in seizure freedom. ${ }^{21}$

There are over 20 AEDs currently licensed for use in the UK. ${ }^{22}$ There are many things to consider when choosing an AED, including epilepsy type or syndrome, side effect profile, comorbidities, drug interactions, potentially teratogenic effects, and patient preference. Table 2 lists (in approximate order of efficiency and tolerability) some of the more commonly used AEDs. Given the results of the SANAD trial in 2007 (a landmark large pragmatic multicentre open-label trial), ${ }^{23,24}$ lamotrigine is generally considered the AED of choice for focal epilepsy and sodium valproate for generalised or unclassified epilepsy. For patients with drug-resistant epilepsy, it is therefore worth trying lamotrigine for focal epilepsy or valproate for generalised epilepsy if they are suitable and have not been tried before. Sodium valproate should be avoided where possible in women of childbearing age, given the evidence for increased teratogenicity and neurodevelopmental problems in children born to mothers taking the drug. ${ }^{25,26}$ Levetiracetam is usually used as an alternative in this case.

There is little good quality evidence to guide choice of AED after the first drug and it is often a matter of trial and error, taking into account individual circumstances. Despite this,

Table 3. Examples of underlying causes of apparent drug-resistant epilepsy in adults.

\begin{tabular}{|c|c|c|c|}
\hline Condition & Clinical clues & Test & Management \\
\hline \multirow{2}{*}{$\begin{array}{l}\text { Autoimmune voltage- } \\
\text { gated potassium } \\
\text { channel encephalitis }\end{array}$} & $\begin{array}{l}\text { Usually late onset drug resistant temporal lobe } \\
\text { epilepsy }\end{array}$ & \multirow[t]{2}{*}{$\begin{array}{l}\text { Voltage-gated potassium } \\
\text { channel complex antibodies }\end{array}$} & \multirow[t]{2}{*}{ Immunosuppression } \\
\hline & Facio-brachial dystonic seizures & & \\
\hline \multirow{2}{*}{$\begin{array}{l}\text { Autoimmune NMDA } \\
\text { receptor encephalitis }\end{array}$} & Usually prominent psychiatric features & \multirow[t]{2}{*}{ NMDA receptor antibodies } & \multirow[t]{2}{*}{ Immunosuppression } \\
\hline & Fairly rapid decrease in mental state & & \\
\hline \multirow[t]{2}{*}{$\begin{array}{l}\text { Glucose transporter } \\
\text { deficiency }\end{array}$} & \multirow{2}{*}{$\begin{array}{l}\text { Typically presents in childhood but can present } \\
\text { in adults; learning difficulties; movement } \\
\text { disorders (ataxia, dystonia, chorea) }\end{array}$} & $\begin{array}{l}\text { Decreased CSF to plasma } \\
\text { glucose ratio }\end{array}$ & \multirow[t]{2}{*}{ Ketogenic diet } \\
\hline & & SLC2A1 gene mutation & \\
\hline Dravet's syndrome & $\begin{array}{l}\text { Progressive severe myoclonic epilepsy, first } \\
\text { seizure usually around the age of six months }\end{array}$ & $\begin{array}{l}80 \% \text { have de novo mutations } \\
\text { in the SCN1A gene }\end{array}$ & $\begin{array}{l}\text { Avoidance of AEDs acting on } \\
\text { the voltage-gated sodium } \\
\text { channel eg lamotrigine }\end{array}$ \\
\hline $\begin{array}{l}\text { POLG-associated } \\
\text { mitochondrial disease }\end{array}$ & $\begin{array}{l}\text { Episodes of status epilepticus early in disease } \\
\text { course, multifocal seizures (occipital lobe } \\
\text { common) neurological signs eg ataxia, raised } \\
\text { CSF lactate, MRI changes }\end{array}$ & $\begin{array}{l}\text { Mutations in the POLG gene } \\
\text { (encodes mitochondrial DNA } \\
\text { polymerase) }\end{array}$ & $\begin{array}{l}\text { Avoidance of sodium } \\
\text { valproate (can precipitate } \\
\text { liver failure) }\end{array}$ \\
\hline
\end{tabular}

AEDs = anti-epileptic drugs; $C S F$ = cerebrospinal fluid; MRI = magnetic resonance imaging; NMDA = N-methyl-D-aspartate receptor; SLC2A1 = solute carrier family 2 , facilitated glucose transporter member 1. 
Table 4. Some of the more commonly used anti-epileptic drugs (AEDs).

\section{Focal epilepsy}

First line

Second line

Other AEDs to consider
Lamotrigine, ${ }^{a}$ levetiracetam, ${ }^{a}$ carbamazepine ${ }^{a}$

Sodium valproate, zonisamide, oxcarbazepine, lacosamide, topiramate, clobazam

\section{Generalised/unclassified}

Sodium valproate, levetiracetam, ${ }^{a}$ lamotrigine ${ }^{a b}$ Zonisamide, clobazam topiramate

Perampanel, eslicarbazepine acetate, gabapentin, phenytoin,

retigabine

${ }^{a}$ Generally considered safer in pregnancy than other AEDs. ${ }^{b}$ May exacerbate absences and myoclonus. AEDs = anti-epileptic drugs.

certain AEDs are more effective than others; Table 2 suggests an order for trying different AEDs, based on the available evidence and the authors' experience.

It is useful to consider the mode of action of the drug when trying a new AED. Table 3 lists the main targets of some of the more commonly used AEDs. If a particular AED has been tolerated but has not been successful in terms of seizure control, it is probably better to then try an AED with a different mode of action. For example, if carbamazepine has been tolerated but has not been successful in a patient with focal epilepsy, it is preferable to try levetiracetam rather than lamotrigine.

Current guidelines recommend that patients normally take the first and second AED as monotherapy. ${ }^{15}$ After this, it is probably worth switching to polytherapy, choosing AEDs with different modes of action. There is some evidence for this approach, with lamotrigine and sodium valproate, for example, having a probable synergistic action when prescribed as polytherapy. ${ }^{27}$ Avoiding the co-prescription of AEDs with the same mode of action also helps reduce the incidence of side effects.

\section{Ketogenic diet}

The ketogenic diet, conceived in the 1920s, is a high fat, low carbohydrate and low protein diet designed to induce ketosis. A landmark randomised control trial in children showed $>50 \%$

\section{Table 5. Main targets of some commonly used AEDs.}

$\begin{array}{ll}\begin{array}{l}\text { Main target } \\ \text { Voltage-gated sodium channel }\end{array} & \begin{array}{l}\text { AED } \\ \text { Carbamazepine, lamotrigine, } \\ \text { oxcarbazepine, lacosamide, } \\ \text { phenytoin, eslicarbazepine } \\ \text { acetate }\end{array} \\ \text { GABA receptor } & \begin{array}{l}\text { Clobazam, phenobarbital } \\ \text { SV2A }\end{array} \\ \text { AMPA glutamate receptor } & \text { Perampanel } \\ \text { Voltage-gated potassium channel } & \text { Retigabine } \\ \text { Voltage-gated calcium channel } & \text { Pregabalin, gabapentin } \\ \text { Multiple mechanisms } & \text { Sodium valproate, topiramate, } \\ & \text { zonisamide }\end{array}$

AEDs = anti-epileptic drugs; AMPA $=\alpha$-amino-3-hydroxy-5methyl-4-isoxazolepropionic acid; GABA $=\gamma$-aminobutyric acid; $\mathrm{SV} 2 \mathrm{~A}=$ synaptic vesicle protein $2 \mathrm{~A}$. reduction in seizures in half of the children treated with the diet. ${ }^{28}$ Current UK guidelines recommend consideration of the diet for children and young people with resistant epilepsy. ${ }^{15}$ There is less evidence for its use in adults although the success rates seem to be broadly similar. ${ }^{29}$ It is of particular relevance as a therapeutic option for people with glucose transporter 1 (GLUT-1) related epilepsy or Dravet syndrome.

The ketogenic diet however is restrictive and not particularly palatable, making adherence to its strict requirements difficult for most people and impossible for some. It is recommended that specialist dietetic support and advice is sought if it is used. Alternative (more palatable) diets such as the modified Atkins diet or medium chain triglyceride diets might become options when better evidence is available. ${ }^{29}$

\section{Other things to consider}

Potentially avoidable factors that can increase the likelihood of seizures include sleep deprivation, consumption of large volumes of alcohol (due mainly to its affect on sleep), and certain drugs (eg tramadol, aminophylline, cocaine and amphetamines). A significant minority of women with epilepsy experience seizure clustering at certain times of their menstrual cycle (catamenial epilepsy). In this instance, it may be useful to consider the co-prescription of an oral contraceptive pill, if appropriate, or an AED such as clobazam to be taken for a few days at the relevant stage of the menstrual cycle. Reflex epilepsies, where certain factors (eg light patterns) will induce seizures, are relatively rare.

Clinicians frequently concentrate on trying to improve seizure frequency in patients with drug-resistant epilepsy. Yet other factors often have more of an effect on the quality of life of a patient with drug-resistant epilepsy. Psychiatric comorbidity (especially depression and anxiety) is common, affecting up to $60 \%$ of patients with resistant epilepsy. ${ }^{30}$ Side effects of AEDs, in particular somnolence, cognitive impairment and dizziness, can be important and difficult to predict, especially when using polytherapy. A compromise between seizure control and side effects in patients with drug-resistant epilepsy is frequently a better approach than trying to achieve complete seizure freedom.

Unfortunately, drug-resistant epilepsy increases the risk of sudden unexpected death in epilepsy, which may be as high as $1 \%$ per year in patients with resistant epilepsy awaiting surgery. ${ }^{31}$ Although it is sometimes a difficult topic to broach within a consultation, it is important that patients and their families and carers are aware of the risk; there are several useful patient information leaflets available. ${ }^{32}$ 


\section{Summary points}

$>$ Drug-resistant epilepsy affects around $20 \%$ of people with epilepsy and carries a significant comorbidity.

$>$ It is important to consider epilepsy mimics and to identify the underlying cause of the epilepsy wherever possible.

$>$ Refer early for epilepsy surgery if appropriate.

$>$ Optimise medical treatment, paying particular attention to the patient's concerns, side effects, comorbidities, previous treatment successes and failures, and the mode of action of anti-epileptic drugs.

$>$ Comorbidities and social stigma in drug-resistant epilepsy frequently have more of an effect on the patient's quality of life than do the seizures themselves.

\section{References}

1 Picot MC, Baldy-Moulinier M, Daurès JP et al. The prevalence of epilepsy and pharmacoresistant epilepsy in adults: a populationbased study in a Western European country. Epilepsia 2008;49:1230-8.

2 Kwan P, Arzimanoglou A, Berg AT et al. Definition of drug resistant epilepsy: consensus proposal by the ad hoc Task Force of the ILAE Commission on Therapeutic Strategies. Epilepsia 2010;51:1069-77.

3 Geerts A, Arts WF, Stroink H et al. Course and outcome of childhood epilepsy: a 15-year follow-up of the Dutch Study of Epilepsy in Childhood. Epilepsia 2010;517:1189-97.

4 Kwan P and Brodie MJ. Early identification of refractory epilepsy. N Engl J Med 2000;342:314-219.

5 Kwan P, Schachter SC and Brodie MJ. Drug-resistant epilepsy. N Engl J Med 2011;365:919-26.

6 McCagh J, Fisk JE and Baker GA. Epilepsy, psychosocial and cognitive functioning. Epilepsy Res 2009;86:1-14.

7 Berg AT, Zelko FA, Levy SR and Testa FM. Age at onset of epilepsy, pharmacoresistance, and cognitive outcomes: a prospective cohort study. Neurology 2012;79:1384-91.

8 Mohanraj R, Norrie J, Stephen LJ et al. Mortality in adults with newly diagnosed and chronic epilepsy: a retrospective comparative study. Lancet Neurol 2006;5:481-7.

9 Sillanpää M, Schmidt D. Is incident drug-resistance of childhood-onset epilepsy reversible? A long-term follow-up study. Brain 2012;135:2256-62.

10 Smith D, Defalla BA and Chadwick DW. The misdiagnosis of epilepsy and the management of refractory epilepsy in a specialist clinic. QJM 1999;92:15-23.

11 Uldall P, Alving J, Hansen LK et al. The misdiagnosis of epilepsy in children admitted to a tertiary epilepsy centre with paroxysmal events. Arch Dis Child 2006;91:219-21.

12 Reuber M and Schachter SC (eds). Borderland of Epilepsy Revisited. London: Oxford University Press, 2012.

13 Devinsky O, Gazzola D and LaFrance WC Jr. Differentiating between nonepileptic and epileptic seizures. Nat Rev Neurol 2011;7:210-20.

14 Schwabe M, Howell SJ, Reuber M. Differential diagnosis of seizure disorders: a conversation analytic approach. Soc Sci Med 2007;65:712-24.

15 National Institute for Health and Care Excellence. The epilepsies: the diagnosis and management of the epilepsies in adults and children in primary and secondary care CG137. London: National Institute for Health and Care Excellence, 2012
16 Freitag $\mathrm{H}$ and Tuxhorn I. Cognitive function in preschool children after epilepsy surgery: rationale for early intervention. Epilepsia 2005;46:561-7.

17 de Tisi J, Bell GS, Peacock JL et al. The long-term outcome of adult epilepsy surgery, patterns of seizure remission, and relapse: a cohort study. Lancet 2011;378:1388-95.

18 Noe K, Sulc V, Wong-Kisiel L et al. Long-term outcomes after nonlesional extratemporal lobe epilepsy surgery. JAMA Neurol 2013;70:1003-8.

19 Englot DJ, Chang EF and Auguste KI. Vagus nerve stimulation for epilepsy: a meta-analysis of efficacy and predictors of response J Neurosurg 2011;115:1248-55.

20 Callaghan BC, Anand K, Hesdorffer D et al. Likelihood of seizure remission in an adult population with refractory epilepsy. Ann Neurol 2007;62:382-9.

21 Luciano AL and Shorvon SD. Results of treatment changes in patients with apparently drug-resistant chronic epilepsy. Ann Neurol 2007;62:375-81.

22 Joint Formulary Committee. British National Formulary (BNF) 66. London, Pharmaceutical Press, 2013.

23 Marson AG, Al-Kharusi AM, Alwaidh M et al. The SANAD study of effectiveness of carbamazepine, gabapentin, lamotrigine, oxcarbazepine, or topiramate for treatment of partial epilepsy: an unblinded randomised controlled trial. Lancet 2007;369:1000-15.

24 Marson AG, Al-Kharusi AM, Alwaidh $\mathrm{M}$ et al. The SANAD study of effectiveness of valproate, lamotrigine, or topiramate for generalised and unclassifiable epilepsy: an unblinded randomised controlled trial. Lancet 2007;369:1016-26.

25 Meador K, Reynolds MW, Crean S et al. Pregnancy outcomes in women with epilepsy: a systematic review and meta-analysis of published pregnancy registries and cohorts. Epilepsy Res 2008; 81:1-13.

26 Meador KJ, Baker GA, Browning $\mathrm{N}$ et al. Fetal antiepileptic drug exposure and cognitive outcomes at age 6 years (NEAD study): a prospective observational study. Lancet Neurol 2013;12:244-52.

27 Brodie MJ, Yuen AWC, and the 105 Study Group. Lamotrigine substitution study: evidence for synergism with sodium valproate? Epilepsy Res 1997;26:423-32.

28 Neal EG, Chaffe H, Schwartz RH et al. The ketogenic diet for the treatment of childhood epilepsy: a randomised controlled trial. Lancet Neurol 2008;7:500-6.

29 Payne NE, Cross JH, Sander JW and Sisodiya SM. The ketogenic and related diets in adolescents and adults-a review. Epilepsia 2011;52:1941-8.

30 Hermann BP and Jones JE. Intractable epilepsy and patterns of psychiatric comorbidity. Adv Neurol 2006;97:367-74.

31 Tomson T, Nashef L and Ryvlin P. Sudden unexpected death in epilepsy: current knowledge and future directions. Lancet Neurol 2008;7:1021-31.

32 SUDEP Action. Leaflets and downloadable information. Available online at www.sudep.org/leaflets-and-downloadable-information [Accessed April 2014].

Address for correspondence: Prof Phil Smith, Welsh Epilepsy Centre, University Hospital of Wales, Cardiff, UK. Email: smithpe@cardiff.ac.uk 